\title{
MULHERES E PROFISSIONAIS DE SAÚDE: O IMAGINÁRIO CULTURAL NA HUMANIZAÇÃO AO PARTO E NASCIMENTO ${ }^{1}$ WOMEN AND HEALTH CARE PROFESSIONALS: THE ROLE OF CULTURAL IMAGINATION IN THE HUMANIZATION OF DELIVERY AND CHILDBIRTH LAS MUJERES Y LOS PROFESIONALES DE LA SALUD: LO IMAGINARIO CULTURAL EN LA HUMANIZACIÓN AL PARTO Y AL NACIMIENTO
}

\author{
Rejane Antonello Griboski², Dirce Guilhem³
}

\begin{abstract}
${ }^{1}$ Este artigo constitui um recorte da dissertação de mestrado intitulada "Humanização do parto à luz da bioética: percepções de mulheres e profissionais da saúde", defendida junto ao Programa de Pós-Graduação em Ciências da Saúde, da Faculdade de Ciências da Saúde, Universidade de Brasília - FS/UnB, em julho de 2004.

2 Enfermeira. Mestre em Ciências da Saúde. Professora Assistente do Departamento de Enfermagem da UnB.

${ }^{3}$ Enfermeira. Doutora em Ciências da Saúde (Bioética). Pós-Doutora em Bioética e Pesquisa com Seres Humanos. Professora Titular do Departamento de Enfermagem da UnB.
\end{abstract}

PALAVRAS-CHAVE: $\mathrm{Hu}$ manização do parto. Vulnerabilidade. Parto.

KEYWORDS: Humanizing delivery. Vulnerability. Parturition.

PALABRAS CLAVE: $\mathrm{Hu}$ manización del parto. Vulnerabilidad. Parto.
RESUMO: Na busca por conhecer o impacto da política de humanização ao parto e nascimento, para mulheres e profissionais de saúde, foi realizada uma pesquisa qualitativa, tomando como referencial metodológico a Análise de Conteúdo e os dados coletados por meio de entrevistas individuais. Os resultados, analisados à luz da Bioética Feminista, apontam que as mulheres vivenciam o processo parturitivo com a sensação de medo e desconhecimento do mesmo; e a humanização, nesse momento, significa submeter-se às ações intervencionistas a elas dirigidas, colocando-as em situação de extrema vulnerabilidade. Os profissionais verbalizam a existência de uma hierarquização nas relações, entre eles e as mulheres, que delimita o espaço social e de saberes. Ficou evidente a falta de comunicação na assistência dispensada por eles às mulheres. $\mathrm{O}$ resgate da autonomia feminina frente ao processo parturitivo e a transformação nas relações interpessoais e profissionais são aspectos relevantes vinculados às mudanças propostas pela Política de Humanização. of humanization on childbirth and birth, a qualitative research was carried out, using as a methodological reference the Content Analysis. The data was collected by means of individual interviews. The results, analyzed in the light of Feminist Bioethics, point out that women live the parturition process with the sensation of fear and unfamiliarity; and humanization, at that moment, means to submit to the interventionist actions directed towards them, putting them in a situation of extreme vulnerability. The professionals verbalize the existence of a hierarchization in the relationships, between them and women, that delimits the social space and knowledge. The lack of communication in the care dedicated by them to women was evident. The rescue of feminine autonomy in view of the parturition process and the transformation in the interpersonal and professional relationships are relevant aspects tied to the changes proposed by the Politics of Humanization.

RESUMEN: En la búsqueda de conocer el impacto de la política de humanización al parto y al nacimiento para mujeres y profesionales de la salud fue realizada una investigación cualitativa, usando como la metodología de referencia el Análisis de Contenido. Los datos fueron recolectados mediante la entrevista individual, así las informaciones obtenidas y analizadas a la luz de la Bioética Feminista apuntan que las mujeres vivencian el proceso de parto y alumbramiento con la sensación de miedo y desconocimiento del mismo; y la humanización en ese momento, significa someterse a las acciones intervencionistas dirigidas, a ellas, colocándolas en situación de vulnerabilidad extrema. Los profesionales verbalizan la existencia de una jerarquización en las relaciones, entre ellos y las mujeres, que delimita el espacio social y de los saberes. Fue evidente la falta de comunicación en la asistencia dispensada por ellos a las mujeres. El rescate de la autonomía femenina frente al proceso de parto y la transformación en las relaciones interpersonales y profesionales son aspectos relevantes vinculados a los cambios propuestos por la Política de Humanización.

Endereço: Rejane Antonello Griboski.

SQN 205, Bl. G, Ap. 602

70.843-070 - Asa Norte, Brasília, DF.

Artigo original: Pesquisa

Recebido em: 15 de agosto de 2005

E-mail: griboski@unb.br

Texto Contexto Enferm, Florianópolis, 2006; 15(1): 107-14 


\section{INTRODUÇÃO}

Mulheres e profissionais de saúde vivenciam o processo parturitivo de forma distinta. A relevância de estudos que permeiam a temática da atenção à saúde pauta-se na crescente preocupação frente à política de humanização dos serviços, em especial no que se refere ao modelo de atendimento prestado por profissionais de saúde às mulheres durante o processo parturitivo. No Brasil, as políticas de saúde da mulher restringiram o atendimento quase que exclusivamente à reprodução humana. Admite-se que essa abordagem, também, ocasionou uma fragmentação no atendimento à mulher, apesar de permitir o acesso ao serviço de saúde à população feminina.

A década de 1980 fez emergir discussões sobre a situação feminina e sua inserção social e nos serviços de saúde. Diante disso, diversos órgãos governamentais e não-governamentais passaram a debater o crescente número de mortes de mulheres, principalmente aquelas ligadas ao ciclo gravídico-puerperal, o que desencadeou uma mudança nas políticas de atenção à saúde da mulher. Em 1984, o Ministério da Saúde instituiu o Programa de Atenção Integral à Saúde da Mulher (PAISM) com a finalidade de adotar uma nova perspectiva de atendimento e oferecer às mulheres uma assistência mais humanizada em todos os níveis de atenção. O Brasil, como participante e signatário das ações recomendadas pela Conferência Internacional sobre População e Desenvolvimento (Cairo, 1994) e pela IV Conferência da Mulher (Pequim, 1995), promulgou portarias que pudessem atuar como instrumentos eficazes no resgate da dívida mundial relativa à discriminação contra a mulher.

Algumas dessas ações efetivaram-se por meio do Programa de Humanização no Pré-natal e Nascimento (PHPN), instituído pela Portaria do Gabinete Ministerial n. ${ }^{\circ}$ 569, de 01/06/2000, do Ministério da Saúde. O enfoque principal desse documento é a mulher e o resgate da dignidade durante o processo parturitivo, buscando consolidar a transformação da atenção prestada durante a gestação, o parto e o puerpério. A implantação do PHPN pode ser considerada um divisor de águas, pois permitiu o diálogo requerido sobre a mudança de condutas e de procedimentos adotados nos serviços, uma vez que o programa prioriza o parto vaginal, a não medicalização do parto e a redução de intervenções cirúrgicas. O documento tece, ainda, uma crítica aos procedimentos que levam à despersonalização da mulher, à realização de operações cesáreas desnecessárias e incentiva o processo de parto ativo como um acontecimento fisiológico. Porém, "o parto vaginal médico moderno parece aos poucos tornar-se um anacronismo, com sua sucessão de procedimentos inúteis, violentos, que aparentemente serviam apenas para confirmar que parir é sofrer". 1:172

No imaginário popular e cultural, destacam-se alguns mitos relativos ao parto: o medo da dor no parto (expresso na referência bíblica: "parirás com dor", castigo imposto a Eva ao ser expulsa do paraíso) a destruição do canal vaginal, o que impediria as mulheres de terem relações sexuais prazerosas, incentivando-se, com isso, a realização da episiotomia ou o parto cirúrgico; e o medo de morrer no parto, transmitido por meio da história de outras pessoas ou familiares. Observa-se, assim, que fatores sócio-culturais podem influenciar a preferência das mulheres pelo parto abdominal, elevando os índices de cesárea. Ao mesmo tempo, há os aspectos físicos, emocionais, afetivos e sexuais que atuam como fatores impeditivos ao estabelecimento de um processo que considere a autonomia e a dignidade das mulheres.

Apesar da argumentação sobre a humanização ao parto, ainda se observa uma vertente centrada no modelo biomédico "visto como emblemático do modo ocidental de pensar e de viver, [o que] implica em questionar o predomínio da técnica e da cultura sobre procedimentos tidos como naturais". 3:487 A perspectiva de humanização no processo parturitivo foi defendida pelo movimento das mulheres, que tomou como base, ainda, as recomendações da Organização Mundial de Saúde sobre as condutas no atendimento ao parto normal. O trabalho de parto e nascimento representa "funções do sistema nervoso autônomo e estão, portanto, fora do controle da consciência", e "humanizar o parto implica em respeitar a natureza biológica, social, cultural e espiritual da mulher". 4:60

Aproximar-se da humanização da assistência permite às mulheres e aos profissionais de saúde desenvolver relações menos desiguais e menos autoritárias. Neste sentido, é essencial o resgate da autonomia e do poder de decisão das mulheres, especificamente, no parto, o seu espaço social e cultural. Percebe-se que o "empoderamento das mulheres passaria pelo resgate dos poderes e saberes femininos que o processo civilizatório teria eliminado ou submetido".3:489

\section{METODOLOGIA}

Este é um estudo qualitativo, desenvolvido a partir das preocupações relatadas, que teve como objetivo apreender a percepção de mulheres e de profis- 
sionais de saúde acerca do impacto ocasionado pela implantação do Programa de Humanização no PréNatal e Nascimento, em um Hospital Universitário. Para alcançá-lo, utilizou-se a Análise de Conteúdo no tratamento analítico dos dados e a Bioética como referencial teórico. A pesquisa qualitativa considera "a compreensão da realidade" como algo "mediado por teoria, por crenças e por representações". 5:17 Ao situar este discurso, é preciso considerar os aspectos culturais e contextuais subjacentes, uma vez que as descrições dos atores estão, freqüentemente, impregnadas de significados, aqui entendidos como crenças e valores adquiridos em suas vivências cotidianas.

A coleta de dados foi realizada no período de setembro a outubro de 2003. Utilizou-se a entrevista semi-estruturada para a aproximação do objeto. Optou-se por um roteiro para a identificação dos respondentes e de duas questões-guia para direcionar as entrevistas, elaboradas em duas versões: uma para as mulheres e outra para os profissionais de saúde. Os sujeitos do estudo constituíram-se de 29 mulheres em situação de pós-parto, identificadas pelos prontuários e nas visitas às enfermarias e de 16 profissionais de saúde ( 5 enfermeiras, 6 médicos staffe 5 médicos residentes em obstetrícia), que estavam vinculados diretamente à atenção ao parto e nascimento. Aos integrantes do estudo foram conferidos letras e números, a fim de preservar-lhes o anonimato.

O cenário de estudo foi a Maternidade. Os aspectos éticos relativos à pesquisa com seres humanos atenderam às diretrizes da Resolução n. ${ }^{\circ}$ 196/96 do Conselho Nacional de Saúde. O projeto foi submetido à avaliação de um Comitê de Ética em Pesquisa e implementado somente após receber o parecer probatório. Cada participante assinou o Termo de Consentimento Livre e Esclarecido e, após esse procedimento, foi realizada a entrevista. As respostas foram gravadas, permitindo-se aos entrevistados expressarem-se livremente sobre os temas abordados, garantindo-lhes o sigilo.

As entrevistas foram transcritas e submetidas a um tratamento analítico informatizado. O objetivo da análise, realizada pelo Software ALCESTE, buscou distinguir as classes de palavras representativas de diferentes formas do discurso acerca do tema pesquisado. A discussão e interpretação dos dados tornaram-se possíveis a partir da Bioética Feminista como referencial teórico, considerando-se, ainda, as experiências vividas no cotidiano.

\section{DESVELANDO AS PERCEPÇÕES DE MULHERES}

Pôde-se apreender que a percepção das mulheres sobre seus corpos e o processo parturitivo contribui para colocá-las em situação de vulnerabilidade. Ficou evidenciado que essa situação perpassa três vertentes, representadas pela vulnerabilidade individual, que diz respeito ao desconhecimento sobre o parto, ao papel que deveriam desempenhar os profissionais de saúde e, principalmente, ao fato de não possuírem uma noção clara de quais seriam seus direitos; vulnerabilidade programática, que se concretiza na forma como o serviço de saúde está organizado, como se estabelece o vínculo com os profissionais de saúde e, ainda, com a própria rotina adotada para o parto; e vulnerabilidade social, a qual emerge claramente na dificuldade de acesso ao serviço de saúde, na falta de leitos hospitalares, no nível elementar de escolaridade e em "todo e qualquer processo de exclusão, discriminação ou enfraquecimento de grupos sociais". $6: 575$ Esses resultados apontam a necessidade de ações voltadas para maior esclarecimento acerca do processo parturitivo a quem de direito (mulheres). Esta categoria apresentou-se com maior expressividade no contexto do presente estudo. Nela, estão inseridas as subcategorias com potencial de dar significação à dimensão do corpo (medicalização do parto) e à subordinação presente no processo parturitivo (submissão das mulheres).

A análise sobre a vulnerabilidade das mulheres no processo parturitivo relaciona-se, principalmente, ao desconhecimento sobre o tipo de assistência que deveria ser prestada e as diretrizes contidas no PHPN. Os principais termos dos quais se pode apreender o significado das palavras, e que expressam as percepções das mulheres em relação ao conhecimento sobre seus direitos e ao tipo de parto, aparecem por meio das expressões: normal, não, hora, direito e os verbos calar, ser, sentir e ficar, conforme os extratos das verbalizacoôes a seguir exemplificadas: [...] direitos eu não sei explicar, eu sei que tenho que ser atendida, da melhor forma possivel, melhor condição, mas todos os direitos, não sei [...] (m19); [...]tratam a gente como se é normal sentir dor, então é normal sentir dor, vai lá conversar, [...] então se você grita, eles fazem você calar a boca, então tudo é normal [...] (m13); [...] não tem lado certo, não tem como ficar, fica virando para lá e para cá, a incomodação dos toques, incomoda muito, acho que fim. Não, não sei declarar. Eu não sabia que poderia ser normal. Não sei varia se fosse normal, talvez sim, talvez não[...] (m10).

Nos discursos das mulheres, fica evidente a existência de uma desvinculação de sua participação no 
processo decisório porque desconhecem seus direitos sexuais e reprodutivos. Com isso, as mulheres contribuem passivamente para a reprodução do modelo biomédico e intervencionista, principalmente quando aceitam resignadamente a conduta imposta. As crenças sobre o seu papel no mundo e sobre o parto refletem-se nas situações sócio-culturais vivenciadas na condição de mulheres e parturientes.

Neste sentido, "o confronto proporcionado pelas crenças e valores - nas diferentes esferas de sua vida em sociedade - e que não lhes permite o exercício da dúvida e da fala", 5:165 pode ser a origem da submissão presente no processo parturitivo. As mulheres condicionadas desconhecem como funcionam seus corpos, seus direitos e os limites vivenciados naquele momento, reforçando a dependência de outro individuo, representado, nesse caso, pelo profissional de saúde. Mas, se não está claro para as mulheres quais seriam seus direitos e como elas podem reivindicá-los, fica difícil transpor a lacuna que lhes permitiriam o exercício da autonomia e o poder de decisão.

Existe, ainda, uma resignação em função do desconhecimento sobre o processo fisiológico do parto por parte das mulheres. Esta postura dá sustentação aos mecanismos de subordinação e opressão assumidos pelas mulheres no contexto hospitalar e, conseqüentemente, as leva a uma situação de vulnerabilidade feminina, refletida na ausência de seus direitos no processo parturitivo. Esse é apenas mais um dos reflexos decorrentes das práticas sociais de gênero, amplamente questionados pela bioética feminista.

Ao aceitar resignadamente o papel que lhes é socialmente imposto, as mulheres confrontam-se com uma forma de opressão considerada como "freqüentemente insidiosa, porque as práticas do indivíduo que a fazem acima do sistema das barreiras podem ver-se como inocentes quando examinadas por si mesmo; seu papel como limitação pode ser obscurecido facilmente". 7:13 A ausência da autonomia é demonstrada por vários aspectos que perpassam o desconhecimento em relação ao atendimento que lhes seria devido e ao papel que deveria ser exercido por quem as assiste.

Durante o processo parturitivo, as mulheres consideram o profissional como aquela pessoa responsável por tirar sua dor. Não sentem curiosidade em saber quem é esse individuo. $\mathrm{Na}$ urgência de resolver seu sofrimento, o profissional ordena e elas obedecem. Os "serviços e profissionais detêm o poder de argumentação que pode se traduzir em formas de opressão e controle, uma vez que a falta de conheci- mento por parte das mulheres sobre seu corpo, os processos reprodutivos e sua própria sexualidade as colocam em situação de vulnerabilidade". 8:166 Vêem-se, então, destituídas do poder decisório, o que limita e impede a expressão de sua vontade.

Nesse cenário de pesquisa, as mulheres colocamse como vetores, isto é, um veículo para proporcionar a passagem de um objeto, nesse caso, o bebê. Para atingir a satisfação individual [procriação] e o sucesso do nascimento de um filho, as mulheres permitem que seus corpos sejam invadidos, medicalizados e controlados como se isso fosse um acontecimento normal. Conforme as expressões verbalizadas pelas mulheres: [...] foi onde aumentaram-se as doses de soro, acho que é para tentar dilatar mais, foi muito sofrido, acho que é um processo normal (M-9.) e, [...] dor que eu achei que ia morrer, a dor da morte, muita contração, ela veio muito forte, chega a ponto de achar que não vai suportar [...] (M-6).

Ao tornar-se vulnerável fisicamente, a maioria das mulheres submete-se a uma situação de ambivalência, causada pelo dilema moral: "medo de não dar conta”. Mesmo quando não suporta a dor, preocupa-se com as pessoas que estão lá fora, pois todos esperam pelo sucesso dela. "A dor objetiva pode vir a ser sofrimento apenas através do olhar de outra pessoa, mas é o olhar profissional, partilhado pela sociedade, que determina a relação do paciente com sua experiência" e "uma dor vivida constitui sofrimento somente se estiver integrada numa cultura" 8:130-5

Essa condição provoca nas mulheres uma dissociação, isto é, a separação ou desagregação do que acontece com elas, como cidadãs, e com seus corpos, durante o processo parturitivo. É como se o corpo não lhes pertencesse. Importa somente o nascimento, o sucesso é esperado por elas e por todos. Essa dissociabilidade envolve as mulheres e as transformam em uma pessoa distanciada do seu parto; fornecem a permissão para serem controladas por outros indivíduos. Sob esta perspectiva, "a mulher não é considerada superior porque reproduz a vida; pelo contrário tornase inferior porque nestas condições sociais a reprodução da vida é uma desvantagem para o controle último do processo social da produção e de dominação" 9:35

Pouco se sabe sobre o sentimento das mulheres, pouco se sabe delas, de como vivem em seus corpos e em seus pensamentos. Portanto, para as mulheres, o processo decisório assume uma forma de subordinação, ao transferir a responsabilidade da decisão para os profissionais de saúde. Essa situação foi apreendida pelas verbalizações nas quais se destaca a 
desinformação gerada pela falta de conhecimento do processo parturitivo e de seus direitos.

\section{DESVELANDO AS PERCEPÇÕES DOS PROFISSIONAIS DE SAÚDE}

A percepção que os profissionais de saúde possuem do processo parturitivo e da implantação do Programa de Humanização no Pré-Natal e Nascimento foi apreendida a partir das verbalizações acerca das inter-relações profissionais e pessoais. Essas verbalizações apontam, claramente, a idéia da existência de uma hierarquização nas relações entre profissionais de saúde e mulheres. Elas são mencionadas como positivas quando favorecem o trabalho do profissional de saúde no ambiente hospitalar, e não o processo parturitivo, transformando a mulher em objeto da ação do outro, onde ela se sujeita ao ordenado. Visto desta forma, o ambiente hospitalar reproduz as desigualdades nas relações de poder presentes no espaço social.

O espaço social é definido como "[...] um conjunto de relações de poder, objetivas que se impõem, elas mesmas, a todos que entram no campo e que são irredutíveis às intenções dos agentes individuais ou mesmo nas suas diretas interações entre os agentes eles mesmos". ${ }^{10: 51}$ E é constituído a partir das diferenças existentes entre os indivíduos ou entre grupos. Nota-se uma "fragmentação do conhecimento na área da saúde e da enfermagem" como sendo um "fator de desumanização do cuidado". ${ }^{11}$ A desigualdade foi percebida a partir da necessidade de mudança nas relações entre os atores, a fim de viabilizar a implantação do Programa de Humanização no Pré-natal e Nascimento.

Essa assimetria torna-se visível no momento do parto, ganhando significado pelas palavras expressas dos profissionais de saúde acerca da assistência ao processo parturitivo. Os termos mulher, bebê, sala de parto (quando se relacionam ao corpo feminino, ao nascimento e ao profissional que atua na assistência ao parto) e os verbos ajudar, decidir, orientar evidenciam a visão que os profissionais de saúde têm sobre o processo decisório exercido pela mulher. Esses significados podem ser identificados por alguns extratos das verbalizações desses atores e que são destacados a seguir: [...] quando a mulher decide e querparticipar ajuda muito, não só, a minha assistência, como aquilo que eu falo para ela, porque eu sou partidário do parto normal. [...] quando a muLher decide ajudar com certeza toda aquela assistência que en vou dar para ela durante o preparo, durante o pré-parto em si, e durante o parto vai ser importante para a minha assistência [...] (s11); e [...] a mãe que entra na sala de parto e que está pronta para ajudar, ai é mais fácil, e as outras não, elas gritam, sentem medo, não querem entrar na sala de parto, fogem da sala de parto [...] (s7).

O profissional de saúde detém o saber cientifico e a técnica para manter sob controle o processo. Isso contribui para a despersonalização da mulher nesse momento. Mesmo quando a mulher participa do parto, essa participação é vista não como efetiva, mas, sobretudo, como uma relação subordinada ao sentido de colaborar com o trabalho profissional.

A situação de despersonalização agrava-se quando "[...] os médicos reproduzem a clássica postura de seu poder inquestionável e do atendimento medicalizado do parto". 12:65 Em seu discurso, o profissional coloca-se como ator principal do parto. A mulher atua como coadjuvante, o seu corpo transforma-se em objeto, ao invés de sujeito principal dessa ação. É nitidamente uma relação assimétrica, na qual o profissional de saúde exerce este papel, centrado no procedimento técnico. Tal relação emerge da fala e da maneira de agir com a mulher: quando ela ajuda, é para favorecer a assistência e não sua própria autonomia.

Desse modo, o corpo feminino é percebido como um meio para subordinação do saber, sobre o qual serão realizados os procedimentos. A lógica da dominação é "[...] exercida em nome de um princípio simbólico conhecido e reconhecido, tanto pelo dominante quanto pelo dominado, de uma língua (ou uma maneira de falar), de um estilo de vida (ou uma maneira de pensar, de falar ou de agir)". 13:8 A história da apropriação do corpo feminino "[...] pelo saber médico foi efetivamente marcada pelo desenvolvimento de um conhecimento cirúrgico e tecnológico promovido pela aproximação da medicina no momento do parto, a partir do qual esse saber se ordena e se sistematiza com o nome de obstetrícia". 14:23

Essa lógica aparece, também, no discurso das enfermeiras, ao reproduzirem a postura feminina de submissão e abstração, perpetuando as relações hierárquicas e a subordinação. Quando elas não impõem ou favorecem outra conduta para as mulheres, reproduzem a rotina hospitalar. O papel da enfermeira é o cuidado prestado a outras pessoas. Esse papel repleto de significados pode apresentar-se com um sentido para a vida das pessoas que estão sendo cuidadas e com outro significado a vida de quem está cuidando. Portanto, a enfermeira, na busca de visibilidade do seu trabalho, pode proporcionar as mudanças necessárias no âmbito da assistência hospitalar, fortalecendo sua capacidade de realizar-se enquanto profissional de saúde. Neste senti- 
do, “[...] é preciso que seja feito um amplo questionamento sobre as estruturas de dominação presentes na sociedade e que perpetuam as situações de vulnerabilidade a que as pessoas são expostas". 6:46

Nos discursos, persiste o desejo da participação das mulheres no processo, decidindo-se por ajudar no parto. Porém, na visão dos profissionais de saúde, elas ainda dependem de sua assistência e, dessa forma, permanecem reféns da técnica. Sua autonomia está garantida somente até o ponto em que ajude, não lhes é permitido opinar sobre seu parto ou como a assistência está sendo prestada. Silencia-se, não pode gritar, permanece isolada, o corpo não lhes pertence; mesmo que as mulheres falem, parece não estarem sendo escutadas.

Durante séculos, têm-se ouvido somente as vozes dos homens. Assim "[...] como vimos mais recentemente a observar não apenas o silêncio das mulheres, mas a dificuldade em ouvir o que dizem quando falam, [...] a falha em ver a diferente realidade das vidas das mulheres e em ouvir as diferenças em suas vozes decorre em parte do pressuposto de que existe um modo apenas de experiência e interpretação social". 15:186 Portanto, diferentemente, devido à complexidade e à particularidade de cada situação, à individualidade dos envolvidos, a maneira como a assistência é oferecida implica na satisfação de quem recebe.

O corpo da mulher "[...] tornou-se propriedade do pessoal médico, permitindo-nos pensar que isso era feito como instrumento de controle social". ${ }^{16: 50} \mathrm{O}$ controle exercido sobre o corpo feminino relaciona-se " [...] ao aprimoramento de uma tecnologia que permitiu a resolução dos problemas cruciais para a sobrevivência das mulheres e crianças, emergindo num momento em que a manutenção da vitalidade e da saúde é fundamental para a reprodução social". ${ }^{14: 23}$ Este controle emerge da prática profissional determinante do tipo de parto, da hora do parto e do nascimento e, também, do uso de medicação para acelerar as contrações. Para o profissional de saúde, o corpo da mulher é sua propriedade no ambiente hospitalar.

No espaço hospitalar, “[...] existe uma série de obstáculos para se implantar uma metodologia de assistência que promova o parto normal [...]" e, 12:106 nesse ambiente, a equipe de saúde parece que "[...] não aceita com tranqüilidade a mobilidade da mulher, e ela própria sente-se pouco à vontade para decidir qualquer coisa a respeito do seu parto". ${ }^{12: 106}$ Desta maneira, pode-se citar, como obstáculos à implantação do Programa, a deficiência de recursos humanos, físicos, materiais, financeiros e a formação acadêmica centrada na intervenção.

Percebe-se, pelas verbalizações dos profissionais de saúde, que, no contexto da assistência, existe a necessidade de uma adequação estrutural, tanto em recursos físicos quanto em maior compromisso dos envolvidos. O sentimento de estarem sozinhos, de falta de união, de falta de engajamento e de atualizações é freqüente na fala dos envolvidos, colocando em evidência a iniqüidade e a injustiça do processo.

Para a viabilidade de implantação de um programa, ou mesmo de uma política, há necessidade dos profissionais de saúde se adequarem ao novo paradigma de assistência. Para isso, torna-se necessário promover mudanças que envolvam desde os órgãos formadores, até a melhoria da infraestrutura hospitalar e das condições de trabalho no atendimento à mulher.

\section{CONSIDERAÇÕES FINAIS}

As propostas de humanização resgatam "a humanidade do atendimento, numa primeira aproximação, é ir contra a violência, já que esta representa a antítese do diálogo, a negação do outro em sua humanidade". ${ }^{17: 9}$ A partir desta proposta, sugere-se "a substituição das formas de violência simbólica, constituintes do modelo de assistência hospitalar, por um modelo centrado na possibilidade de comunicação e diálogo entre usuários, profissionais e gestores, busca instituir uma nova cultura de atendimento". ${ }^{17: 9}$ Neste sentido, a humanização possibilita uma reorganização dos serviços de assistência à saúde das mulheres, resgatando e promovendo o respeito pela condição feminina e o respeito por um atendimento mais digno e de qualidade.

A reflexão sobre a vulnerabilidade feminina foi um aspecto verificado no estudo e relaciona-se à inexistência de vínculos mais afetivos e ao desconhecimento do tipo de assistência prestada. Essa desvinculação e esse desconhecimento geram nas mulheres uma limitação sobre o seu poder de decisão, o que leva à percepção de que é natural sentirem-se submissas e maltratadas. Esse poder de decisão foi apropriado pelos profissionais de saúde quando passaram a determinar o tipo de assistência e o tipo de parto ao qual as mulheres serão submetidas. A existência de relações assimétricas presentes no atendimento está representada pelo desconhecimento acerca dos acontecimentos relacionados ao processo parturitivo e de direitos, uma vez que às mulheres vem sendo negado tradicionalmente o acesso a esse conhecimento. 
A subordinação das mulheres é vista como "um arranjo cultural muito bem estabelecido, que continua a ser mantida por muitas das principais instituições e dos valores da moderna sociedade". A subordinação, também, é sustentada pelas principais religiões que reforçam o privilégio do macho e perpetuam a dominação masculina tratando a questão como um acontecimento habitual. Assim, a opressão naturalizada nos hábitos torna difícil a conscientização de que as mulheres estão em situação de desigualdade, necessitando de um amplo processo de aprendizado para reverter essa situação e reconhecer que existem barreiras culturalmente impostas.

Para que o processo de mudança ocorra, tornase necessário que os serviços de saúde passem a ser locais em que as mulheres possam ser orientadas e esclarecidas sobre direitos sexuais, reprodutivos, tipos de parto, políticas de saúde, violência sexual e física. E sobre ações que podem ser executadas durante o prénatal, capacitando-as, assim, como agentes ativas nas mudanças e tomada de decisão, a fim de minimizar o viés hierárquico do modelo assistencial e de gênero presente na assistência prestada às mulheres no processo parturitivo.

Revelou-se a resistência dos profissionais, que também se dá por desconhecerem outra forma de atendimento, apontando para a necessidade de adequação ao novo modelo, já que não foram preparados pelas universidades para atuarem de forma diferenciada. Acreditam que um fator decisivo para efetivar a mudança está vinculado à melhoria de recursos humanos e físicos, a uma remuneração adequada, assim como à sensibilização e ao treinamento em serviço, especialmente antes, durante e depois da implantação do programa. Um grande desafio está direcionado às políticas públicas, no sentido de contribuir para a efetivação da premissa da eqüidade - política, jurídica, social e econômica - e para a desconstrução do modelo de medicalização do corpo feminino e, conseqüentemente, do parto.

A universidade, como órgão formador desses profissionais, no sentido de complementar o projeto político-pedagógico, pode inserir nos currículos questões que desenvolvam a capacidade reflexiva, ética, política, psicológica e humanística em relação ao atendimento e ao usuário, visando à formação integral e ao respeito pela pluralidade de valores presentes na sociedade. Para isso, tem-se claro que as Políticas do Ministério da Saúde, na tentativa de privilegiar a formação de profissionais nãomédicos para o atendimento ao parto, estendeu às enfermeiras obstétricas e à criação das casas de parto, parte da responsabilidade dessas mudanças.
Neste contexto, a existência de uma aproximação no enfoque do cuidado na ética e na bioética feministas "tem como objetivo principal a reabilitação de valores femininos culturalmente associados como a compaixão, a empatia, a simpatia, a essência e a bondade", assumindo "como seu principal imperativo a eliminação ou a modificação de todo o sistema estruturado ou ajustado de normas, incluindo regras éticas que contribui para a opressão humana, particularmente, opressão de mulheres" ${ }^{18: 28}$ A enfermeira deve assumir o ônus da mudança, já que é reconhecida como o agente que possui vínculo mais estreito com a mulher.

Como resultado final da pesquisa, torna-se emergente criar uma aliança sólida entre os profissionais de saúde e as mulheres. O grande mérito dessa postura reside na importância de priorizar o direito de escolher qual a alternativa de assistência ao parto mais bem adaptada à necessidade e à vontade da mulher. No entanto, para atingir o desejado pelas mulheres, elas também precisam se apropriar do conhecimento de seus corpos, de seus direitos e assumir o controle das ações que são impostas pelas políticas públicas, por meio da participação ativa na elaboração dessas políticas.

Para o futuro, os profissionais de saúde buscam assumir o compromisso de modificar a assistência ao parto e nascimento a partir de estudos baseados em evidências cientificas, proporcionando um novo pensamento e conscientização dos direitos da mulher. Enquanto isso, as políticas públicas viabilizam a possibilidade de acesso ao serviço e ao empoderamento, tanto das mulheres como dos profissionais de saúde. Não se pode perder de vista que, se o nascimento "[...] é o espelho da cultura de um povo, já estamos na hora de sentar junto e repensar a assistência que, como sociedade, prestamos à mulher no ciclo grávido puerperal". 19:104

\section{REFERÊNCIAS}

1 Diniz CSG. Assistência ao parto e relações de gênero: elementos para uma releitura médico-social [dissertação]. São Paulo: Faculdade de Medicina da Universidade de São Paulo; 1997.

2 Gênesis 3,16. A bíblia sagrada. 2a ed. São Paulo: Sociedade Bíblica do Brasil; 1993. p.5.

3 Tornquist CS. Armadilhas da nova era: natureza e maternidade no ideário da humanização do parto. Rio de Janeiro. Rev. Estudos Feministas. 2002 Jul-Dez; 10(2):483-92.

4 Taveiros W. Assistência ao parto humanizado. In: IV Seminário Estadual Qualidade da Assistência ao Parto: contribuições da enfermagem; 2001 Jun 27-29; Curitiba, Brasil. Curitiba: ABEn/ABENFO; 2001. p. 60. 
5 Minayo MCS, Deslandes SF, organizadores. Caminhos do pensamento: epistemologia e método. Rio de Janeiro: FIOCRUZ; 2002.

6 Palma A, Mattos UAO. Contribuições da ciência pósnormal à saúde pública e a questão da vulnerabilidade social. Rev. História, Ciências e Saúde. 2001 Set-Dez; VIII(3):567-90.

7 Guilhem D. Escravas do risco: Bioética, mulheres e Aids [tese]. Brasília: Faculdade de Ciências da Saúde da Universidade de Brasília; 2000.

8 Illich I. A expropriação da saúde: nêmesis da medicina. 4a ed. Rio de Janeiro: Nova Fronteira; 1981.

9 Vaitsman J. Biologia e história: ou, por que a igualdade é possível. In: Labra ME. Mulher, saúde e sociedade no Brasil. Petrópolis: Vozes; 1989. p.25-38.

10 Rausch D. Sobre a cosmovisão: a proposta topológica de Pierre Bourdieu e o interacionalismo simbólico. Boletim CLCH. 1993 1º Sem.; 24(1):51-60.

11 Wendhausen ALP, Rivera S. O cuidado de si como princípio ético do trabalho de enfermagem. Texto Contexto Enferm. 2005 Jan-Mar; 14(1): 111-9.

12 Osava RT. Assistência ao parto no Brasil: o lugar do nãomédico [tese]. São Paulo: Faculdade de Saúde Pública da Universidade de São Paulo; 1997.
13 Bourdieu P. A dominação masculina. 2a ed. Rio de Janeiro: Bertrand Brasil; 2002.

14 Vieira EM. A medicalização do corpo feminino. Rio de Janeiro: FIOCRUZ; 2002.

15 Gilligan C. Uma voz diferente: psicologia da diferença entre homens e mulheres da infância à idade adulta. Rio de Janeiro: Rosa dos Tempos; 1990.

16 Melo CRM. Parto: mitos construídos, mitos em construção. Bauru: EDUSC, 2003.

17 Deslandes SF. Análise do discurso oficial sobre a humanização da assistência hospitalar. Ciência Saúde Coletiva. 2004 Jan-Mar; 9(1): 7-14.

18 Tong R. Is a global bioethics possible as well as desirable?: a millennial feminist Response. In: Tong R, Anderson G, Santos A. Globalizing feminist bioethics. crosscultural perspectives. Tennessee (USA): Westview Press; 2001. p. 27-36.

19 Largura M. Assistência ao parto no Brasil: aspectos espirituais, psicológicos, biológicos e sociais - uma análise crítica, por um parto mais humano e solidário. 2a ed. São Paulo: Ed. Autor; 2000. 